\title{
A PERSPECTIVA ECO-RELACIONAL E PAULO FREIRE: CONTRIBUIÇÕES PARA PENSAR A FORMAÇÃO DE PROFESSORES NA EDUCAÇÃO A DISTÂNCIA
}

\author{
FORTALEZA/CE MAIO/2018 \\ $\begin{array}{cc}\text { Pedro Henrique Alves Camelo } & \text { - TCE/CE - pedro@tce.ce.gov.br } \\ \text { Francisco Otávio de Miranda Bezerra } & \text { - TCE/CE - fotavio@tce.ce.gov.br }\end{array}$ \\ Tipo: Relato de Experiência Inovadora (EI) \\ Categoria: Métodos e Tecnologias \\ Setor Educacional: EDUCAÇÃO CORPORATIVA \\ RESUMO
}

\begin{abstract}
Resumo
Este artigo apresenta a Perspectiva Eco-Relacional (PER) (Figueiredo, 2003), em sua interface com a Pedagogia Freireana (1994, 1996, 2005), no intuito de possibilitar reflexões acerca da Formação de Professores da Educação a Distância (EaD). A PER propõe se distanciar da lógica individualista e individualizante de ensino, ela avança numa lógica eco-relacional. Essa Metodologia é fundamentada em Metáforas Categoriais, com os aportes de Paulo Freire. Nosso intuito é mostrar uma proposta de formação que se realiza com os estudantes e não, simplesmente, para eles. Ela vem sendo aplicada pelos professores do Instituto Plácido Castelo (IPC), órgão de educação corporativa do Tribunal de Contas do Estado do Ceará (TCE/CE), por meio de formações conduzidas por especialistas do seu Núcleo de Educação a Distância (NEAD). O IPC disponibiliza gratuitamente via Internet, oportunidades de capacitação, visando o desenvolvimento e o aperfeiçoamento para os servidores públicos estaduais, municipais e a sociedade do Ceará, atendendo anualmente mais de 15.000 alunos. Nesse sentido, a opção pela PER objetiva possibilitar, mais ainda, a aproximação da ferramenta da informática com o diálogo dos estudantes e professores. Sendo assim, algo que privilegie o estudante como autor de sua própria trajetória de formação. Ressalte-se que vários cursos já foram ofertados pelo IPC com essa Metodologia, e como resultado prático, destacamos o Curso Educação e Gestão Ambiental ofertado para 300 alunos, com apenas $18 \%$ de evasão. Ademais, nos relatos espontâneos das avaliações dos participantes, muitos destacaram o nível de aproximação dos estudantes com os colegas e com os professores, fator esse que nos estimularam a compartilhar a presente experiência.
\end{abstract}

Palavras-chave: Perspectiva Eco-Relacional, Educação Dialógica, Formação Docente

\section{AGRADECIMENTOS}

COMO PEDAGOGO E PESQUISADOR DA EDUCAÇÃO A DISTÂNCIA, AGRADEÇO AO TRIBUNAL DE CONTAS DO ESTADO DO CEARÁ, EM PODER CONTRIBUIR COM O TRABALHO DE OFERTAS DE CURSOS GRATUITOS PARA SERVIDORES E À SOCIEDADE. 


\section{Introdução}

Oobjetivo deste artigo é apresentar a Perspectiva Eco-Relacional (PER) (FIGUEIREDO, 2003), em sua interface com a Pedagogia Freireana (1994, 1996, 2005), no intuito de possibilitar algumas reflexões acerca da formação de professores, tendo como referência mais específica a formação de professores em educação a distância. A PER propõe se distancia da lógica individualista e individualizante do ensino, e avançar numa lógica eco-relacional.Essa Metodologia é fundamentada em Metáforas Categorias, com os aportes de Paulo Freire. Não temos aqui a pretensão de indicar caminhos para guiar a formação, mas potencializar reflexões críticas que nos permitam pensar a Educação a Distância cada vez mais próxima dos estudantes. Entendemos que toda metodologia aplicada nos processos educacionais é permeada por uma concepção epistemológica, ou seja, pela forma como se acredita ou deseja que a construção do conhecimento aconteça. Nesse sentido, acreditamos que a Educação a Distância (EaD) precisa ser cada vez mais dialógica, pois a distância física entre alunos e professores não deve impedir que relações humanas sejam estabelecidas. Todavia, para que tal prática aconteça, é necessário buscar subsídios teóricos que a fundamentem.

Por esta razão, o Instituto Plácido Castelo (IPC), órgão de educação corporativa do Tribunal de Contas do Estado do Ceará vem investindo nesse trabalho de formação com seus professores, contando com uma coordenação pedagógica e professores que periodicamente participam de oficinas para estudos e análises críticas dos resultados de suas realizações. Como resultado da aplicabilidade da Metodologia das Metáforas Categorias, apresentamos o Curso Educação e Gestão Ambiental ofertado por meio do Ambiente Virtual de Aprendizagem AVA/IPC, com a participação de 02 dois professores e 300 alunos.

\section{Educação a Distância}

Tradicionalmente, a Educação a Distância $(\mathrm{EaD})$ foi definida como uma modalidade educacional caracterizada pela separação física entre o professor e o aluno, e o uso intensivo da tecnologia. Tal concepção preocupava-se em contrapor a $\mathrm{EaD}$ ao ensino convencional, sendo a relação professor-aluno "controlada" por regras técnicas mais do que normas sociais. Conforme Van Lier (1996), existem múltiplas formas de interação na relação professor-aluno. O autor classifica as relações construídas que vai do autoritário, 
passando por autoritativo e chegando a exploratório. A primeira (relação autoritária) refere-se à educação tradicional, marcada pela exposição monóloga e unidirecional do professor. Já na segunda (relação autoritativa), o processo de comunicação alunoprofessor passa a ter vez, porém ainda sob o controle do professor. Finalmente, com a terceira posição (relação exploratória), é o caminho da Educação Dialógica.

\section{A Perspectiva Eco-Relacional e a Proposta Freireana na Formação de Professores em EaD}

A PER traz como contribuição fundamental a inclusão da dimensão sócio- histórica, ecológica e política, rumo a uma perspectiva mais abrangente, que torna a 'relação' um eixo principal da práxis, saindo da visão antropocêntrica, ainda verificada em algumas obras de Freire, e seguindo rumo a uma visão que inclui os contributos "dos novos paradigmas epistemológicos oriundos da quântica e da ecologia" (FIGUEIREDO, 2007, p. 11), bem como inclui a urgência de se pensar os processos formativos em sintonia com as questões ecológicas e ambientais. (Figueiredo,2007).

O sentido eco-relacional é entendido como leitura de mundo que realça "a importância fundamental das relações, sejam elas humanas, sociais ou ecológicas, considerando a relevância de relações não antropocêntricas" (FIGUEIREDO, 2004, p. 18). A PER também identifica as relações como a forma de ser de tudo no mundo (sentido, pensado ou vivido), expressando o equívoco das percepções fragmentárias. Insere-se "em propostas que retomem valores ético-morais não antropocêntricos, não fragmentários, fundamentalmente relacionais, melhor dizendo, eco-relacionais" (FIGUEIREDO, 2007, p. 55).

Para além da dimensão relacional e afetiva, a PER traz ainda como categorias fundamentais a dialógica, a contextualização, a supra-alteridade, o saber parceiro, a compreensão do grupo-autor, as múltiplas linguagens e a ecopráxis, que contribuem para edificar um projeto de formação integral, axiológico, ontológico no 'ser mais', corroborando com Freire, ao conceber a educação como um instrumento necessário à luta, para a superação das condições desumanizantes que perpassam também os processos formativos.

A formação docente, em sua dinâmica relacional, materializa-se no compartilhamento que se dá nas relações parceiras, democráticas, que se revestem de integralidade, de superação dos modelos colonializantes, subalternizantes, que oprimem os humanos em sua caminhada na direção do seu ser mais. Assim, a formação é concebida como um 
instrumento necessário ao enfrentamento, bem ao gosto de Paulo Freire (1983), para a superação das condições desumanizantes que ainda perpassam muitos processos formativos. (Figueiredo, 2007).

Mais do que aprofundar questões relativas somente às problemáticas da formação de professores da EaD, trazemos de Freire (1994, 1996, 2005), em sua busca incessante por uma educação dialógica, problematizadora, transformadora e humana. A sua ênfase na capacidade ontológica própria do humano de "ser mais", de superar as "situações limites" e avançar rumo aos sonhos possíveis, que se faz por meio do percurso que transita da curiosidade ingênua para curiosidade epistemológica, por compreender que esses aportes são essenciais para pensar a formação de professores e suas práxis (ação e reação).

O sentido de inconclusão do humano e sua busca permanente, indo da curiosidade ingênua para a curiosidade epistemológica, indica que a docência não pode desvincular da pesquisa, da problematização, da pergunta constante, da reflexão sobre as perguntas e tentativas de respostas. Nesse sentido, a formação de professores deve também constituir como um caminho através do qual essa percepção de inconclusão seja possível. Outra contribuição de Freire (1996) é a importância da problematização para o ato educativo, que não se descola também da dialógica. Na ação de se problematizar, de buscar respostas para as indagações, o humano se transforma e transforma a sua própria realidade. Assim, acreditamos que as contribuições da PER e Paulo Freire são essenciais para se pensar a formação de professores em EaD. Concordando com Nóvoa (1992) quando afirma:

A formação deve estimular uma perspectiva crítico-reflexiva, que forneça aos professores os meios de um pensamento autônomo e que facilite as dinâmicas de autoformação participada. Estar em formação implica um investimento pessoal, um trabalho livre e criativo sobre os percursos e os projetos próprios, com vistas à construção de uma identidade que é também uma identidade profissional (p.25).

\section{As Metáforas Categoriais aplicadas nos Cursos a Distância}

Na educação corporativa a nossa busca do conteúdo programático para elaboração de curso a distância começa com a investigação dos temas geradores. Esses temas compreendem as ideias, concepções, esperanças, dúvidas, valores e desafios do 
educando, concebidos em sua relação com o mundo. Freire (2005), denomina universo temático. São considerados geradores porque, qualquer que seja a natureza de sua compreensão como a ação por eles provocadas, possibilita se desdobrarem em outros temas, novos olhares e perspectivas de compreensões do universo em discussão.

Para Freire (2005), o processo do diálogo na perspectiva educativa deve se estabelecer na direção que tenha por fim levar os humanos a despertarem seu potencial crítico para desvelamento do mundo e possam, dessa forma, transformá-lo através de sua práxis. $\mathrm{O}$ diálogo no espaço online possibilita o saber parceiro, reconhecendo que as discussões nos fóruns e outras ferramentas se constituem em espaços para a construção de saberes coletivos. Isto potencializa um grau de confiabilidade entre todos e, ao mesmo tempo de empatia. Segundo Figueiredo (2007), o saber parceiro propicia que se amplie a autoestima pela valorização dos saberes individuais para o crescimento do coletivo, no qual se estabelece também uma dimensão de corresponsabilidade, ou seja, a compreensão do coletivo como teia, demonstrando que todos influenciamos e somos influenciados pelos outros.

Portanto, a aplicação das Metáforas Categorias da PER começa desde a etapa de construção do conteúdo programático. O conteúdo programático deve ser organizado a partir da situação presente, existente e concreta do aluno, a fim de refletir suas aspirações. Nessa perspectiva, para que haja comunicação entre professores e alunos é necessário a valorização dos conhecimentos e respeitos às culturas. Há de se reconhecer que nas formalidades e informalidades presentes e necessárias na condução de curso online, as dimensões educativas são estabelecidas pelas trocas.

Segundo Carlos Brandão (2004), "a educação é, como outras, uma fração do modo de vida dos grupos sociais que a criam e recriam, entre outras invenções de sua cultura, em sua sociedade." Nesse sentido, a metodologia da PER aplicada nos cursos, além das contribuições de Paulo Freire e Carlos Brandão, também é baseada nas Metáforas Categoriais do educador Figueiredo (2007). Entendemos que as Metáforas Categoriais de Figueiredo (2007) partem do pressuposto de que o Ensino na Modalidade Virtual em processos de formação oferece uma outra lógica que não se esgota em si mesma. É uma abertura constante ao diálogo, ao diferente, ao imprevisível, ao grupal. As Metáforas Categoriais são dialogais e propõem romper com a lógica:

Cognitivista e opressora; individualista e individualizante de ensino; conteudística; da neutralidade científica; da formação por meio da transmissão de conhecimentos; de que alguém é o proprietário dos saberes essenciais à formação; autoritária ou liberal; da 
teoria da ação bancária; cartesiana e fragmentária; de uma educação tradicional focada no professor; escolanovista focada no aluno e avança numa lógica eco-relacional (Figueiredo, 2007).

É uma epistemologia vivencial e experiencial voltada para a teia de relações, que repercute numa lógica que considera a totalidade das relações interligadas e interatuantes. Pretende uma ação-reflexão-ação transformadora, que ao considerar os temas geradores apontados no curso, possibilita também a inclusão das dimensões histórico-política e sócio-cultural dos alunos e tutores. Exemplos de Metáforas Categorias da PER trabalhadas pelos tutores e alunos no desenvolvimento dos temas geradores dos cursos:

Supra Alteridade - Possibilitar o diálogo e respeito entre os diferentes, onde a contribuição de cada pessoa favorece a ampliação dos conhecimentos coletivos. Ou seja, o respeito ao colega e a compreensão da contribuição de cada um para a ampliação dos conhecimentos abordados nos módulos do curso. Saber Parceiro - As diferenças e diversidades de ideias se confundem com o que é meu e o que é do outro. O diálogo e a troca de experiências contribuem para a formação de novos saberes. Em relação ao curso, o saber parceiro propicia que se amplie a autoestima, pela valorização dos saberes individuais, para o crescimento do coletivo; no qual se estabelece também uma dimensão de corresponsabilidade, ou seja, a compreensão do coletivo como teia, demonstrando que todos influenciamos e somos influenciados pelos outros. Afetividade - Ponto de apoio na relação alunos - professores. Contextualização - As vivências individuais para o contexto, viabilizam relações dialogais. Em relação aos temas do curso online, a contextualização com as vivências dos integrantes caminham em busca de ressignificação de ideias, objetivos etc.

\section{A Construção Coletiva do Curso e seus Resultados}

O curso Educação e Gestão Ambiental foi construído com os temas geradores indicados pelos alunos, com participações de servidores públicos das diversas áreas de atuação da Gestão Pública do Ceará, e ao público em geral. Destacamos que o curso contou com servidores das esferas estadual do Legislativo, Executivo e Judiciário, bem como de ouvidores de prefeituras, e de diretores, professores, alunos e conselheiros de escolas públicas do Estado do Ceará. A oferta de cursos a distância faz parte do papel educativo do Instituto Plácido Castelo de contribuir com o Tribunal de Contas do Ceará, em sua missão de assegurar à sociedade a regular e efetiva gestão de recursos 
públicos, mediante o controle externo da Administração Pública, nos valores da justiça, da efetividade e da transparência. Por meio de ações pedagógicas, dentre essas, realizações de cursos gratuitos para servidores públicos e à sociedade, com temáticas diversas, inclusive sobre a preservação do patrimônio e ambiental, atendendo anualmente cerca de 15.000 alunos em seus cursos online.

O curso Educação e Gestão Ambiental foi ofertado com a carga horária de 20horas, divididas em 04 (quatro) módulos, por meio da Plataforma de Educação a Distância do IPC, ou, Ambiente Virtual de Aprendizagem (AVA), contando com a participação de 300 alunos, dialogando com dois professores que se revezavam em todo o decorrer do curso.O grande desafio para os professores e estudantes do curso foi a "construção coletiva" de um Projeto de Educação e Gestão Ambiental. No caminhar desse projeto coletivo, percebemos alguns limites a serem enfrentados, tanto na constituição do grupo quanto na sua manutenção, que nos pareceram estar associados à ideia de resistência e disputas pelo poder. Estes parecem ocorrer com estudantes ressabiados pelas relações pedagógicas tradicionais nas quais há imposição de conteúdos e atitudes prédefinidas pelos docentes. Dentre estes limites, queremos apresentar a dificuldade de se aceitar o novo, o desconhecido. Alguns estudantes estranharam as estratégias e a maneira como os professores interagiam com eles. Ficavam como que esperando a armadilha que acreditavam existir naquelas ações. Em alguns momentos acreditaram que o projeto coletivo não daria resultado. Nesse desafio, a aplicabilidade das Metáforas Categorias da PER, e as contribuições de Paulo Freire, se fizeram presente na consolidação de um Amplo Projeto Parceiro, contemplando as problemáticas sócio ambientais, bem como propostas para a Educação e a Gestão Ambiental.

\section{Considerações sobre os resultados}

Ressaltamos que para a avaliação dos resultados do curso, como participação de alunos, professores, coordenação, interação entre eles, índice de evasão, aprovação e satisfação, ferramentas foram disponibilizadas no Ambiente Virtual de Aprendizagem, a se ver:

- Comentários, Críticas, Sugestões; Controle de acesso ao AVA/IPC (por aluno e professor);

- Controle de tempo e execução das tarefas disponibilizadas (por aluno); 
- Relatório de notas (por aluno e geral); Participação nos debates dos fóruns (por aluno e professor);

- Avaliação de satisfação do curso (individual e geral);

\section{Considerações finais}

Este artigo teve como objetivo apresentar a Perspectiva Eco-Relacional (PER) (Figueiredo, 2003), em sua interface com a Pedagogia Freireana (1994, 1996, 2005), no intuito de possibilitar reflexões acerca da Formação de Professores da Educação a Distância (EaD). Sabemos que o trabalho de formação não resolve todos os problemas e dilemas a serem enfrentados pelo professor em sua práxis docente, tendo em vista o grande desafio que é a proximidade com as tecnologias que mediam as práticas educativas. Entretanto, o Instituto Plácido Castelo, órgão de educação corporativa do Tribunal de Contas do Estado do Ceará, por desenvolver amplo trabalho de ofertas de cursos gratuitos a distância para o público de servidores públicos e à sociedade, vem investido na formação de seus professores, consideramo que a Educação Dialógica aplicada nos cursos de Educação a Distância oferece significativa contribuição, como a dialógica e o diálogo, fatores imprescindíveis para os processos democráticos nas relações, o respeito a diversidade e pluralidade de ideias e manifestações, e o saber parceiro, ao possibilitar uma leitura de respeito pelos saberes compartilhados que se fazem novos saberes nas mais diversas dimensões da vida.

\section{Referências}

BRANDÃO, Carlos Rodrigues. O que é Educação. São Paulo - SP: Ed.Brasiliense (Coleção primeiro passos), 2004.

FREIRE, Paulo. Pedagogia da Esperança: um reencontro com a pedagogia do oprimido. 3 ed. Rio de Janeiro/RJ: Paz e Terra, 1994.

, Paulo. Pedagogia da Autonomia: saberes necessários para a prática 
educativa. São Paulo: Paz e Terra, 1996.

Paulo. Pedagogia do Oprimido. 25. ed. Rio de Janeiro: Paz e Terra,

1998.

Paulo. Educação como prática da Liberdade. Rio de Janeiro/RJ: Paz e

Terra, 2000.

Paulo. Pedagogia do Oprimido. 41. ed. Rio de Janeiro: Paz e Terra, 2005.

FIGUEIREDO, João B. A. Educação ambiental e dialógica e representações sociais da água em cultura sertaneja nordestina: uma contribuição à consciência ambiental em Irauçuba-Ce. Tese (Doutorado). Universidade Federal de São Carlos UFSCar, São Carlos-SP, 2003).

João B. A. e OLIVEIRA, Haydée Torres. Educação ambiental dialógica e trajetória de sentido nos bairros de Irauçuca/Ce. Editora UFC, 끙, 2004.

João B. A. Educação Ambiental Dialógica: a contextualização do ensino numa leitura de Paulo Freire. In: FIGUEIREDO, J. B. A. ; OLINDA, E.M.B. (Orgs.). Formação humana e dialogicidade em Paulo Freire. Fortaleza/Ce: Ed. UFC, 2006.

João B. A. Educação ambiental e o educador em formação numa perspectiva eco relacional. In: Associação Nacional de Pesquisa e Pós-Graduação em

Educação - ANPED, 2007. Caxambu, 2007.

NÓVOA, Antônio. Formação de professores e profissão docente. In: NÓVOA, A. (Org.). Os professores e a sua formação. Lisboa: Dom Quixote, 1992.

VAN LIER, L. Interaction in the language curriculum: awareness, autonomy and authenticity. London: Longman, 
